\title{
The Pragmatic Functions and Prosodic Features of the Sentence-Final Particle "ba" in the Imperatives
}

\author{
Dong Fangliang ${ }^{1,}$, Chen Xiangyue ${ }^{1}$, He Rui $^{2}$ \\ ${ }^{1}$ College of Foreign Studies, Jinan University, Guangzhou, China \\ ${ }^{2}$ School of Translation Studies, Jinan University, Zhuhai, China \\ Email address: \\ dfl2002@163.com (Dong Fangliang),1916897995@qq.com (Chen Xiangyue),h.h-horace@outlook.com (He Rui) \\ ${ }^{*}$ Corresponding author
}

\section{To cite this article:}

Dong Fangliang, Chen Xiangyue, He Rui. The Pragmatic Functions and Prosodic Features of the Sentence-Final Particle "ba" in the Imperatives. Communication and Linguistics Studies. Vol. 4, No. 3, 2018, pp. 80-87. doi: 10.11648/j.cls.20180403.13

Received: August 15, 2018; Accepted: September 11, 2018; Published: October 12, 2018

\begin{abstract}
Ba" is one of the common used sentence-final particle in Chinese. This paper studies the spoken language of film and television drama to analyze and verify the pragmatic functions of "ba" by means of the multidimensional study of language form, meaning, pragmatics and phonetics. First, from the perspective of different category distribution of the imperative sentence, it probes into the distribution rules of "ba", the co-occurrence with adverbs, auxiliary verbs etc, and reveals the grammatical meaning. Statistical analysis shows that the use of modal particles is the "marked form" of the imperative sentence. Among them, "ba" is the most frequently used, and its core meaning is "Suggestion Discussion". Secondly, through the semantic analysis of "ba" in terms of Discourse Politeness Theory, it concludes that "ba" can serve the purpose of softening the manner of speaking and the degree of courtesy/discourtesy. Thirdly, from the perspective of phonetic experiment, the phonetic features of the sentence-final particle "ba" under different functions, were observed and analyzed, which again verified the rationality of our pragmatic classification. Thus, it is proved that the elements of language do not exist in isolation, and the characteristics of function words such as sentence-final particle can be better revealed by studying them from the comprehensive perspective of form, meaning, pragmatics and phonetics.
\end{abstract}

Keywords: Sentence-Final Particle, Function Distribution, Semantic Co-Occurrence

\section{Introduction}

As one of the typical Chinese modal particle, ba has always been the focus but also difficulty of grammatical research. The previous researchers tended to focus on its multiple textual meaning [1-4]. After the introduction of structuralism to China, some researchers tried to make a description of its distribution and usage [5; 6] Meanwhile, some researchers, represented by Lu Yuming (1984) and $\mathrm{Hu}$ Mingyang (1981), tried another way. They attempted to define the core meaning and usage of ba with analysis of its numerous different textual meanings and usage. Afterwards, researchers started to carry out a more comprehensive study on the core meaning of ba with respect to textual function, modal characteristics and pragmatic function and finally defined it as expression of hesitation [7-10]. Mr. Ran Yongping pointed out in 2004 that besides its function of increasing moderation and negotiation of tone, ba also has pragmatic function as moderation and contextual adaptation in specific context of communication. With various research techniques and from various perspectives, previous researchers have carried out comprehensive and detailed study on the grammatical meaning, form mark and pragmatic function of ba. However, there remain some failings: (1) Most of the researches focus on written works especially on literary works rather than on oral language materials, paying few attentions to the usage of modal particle in oral language. (2) There is deficiency in the oral-corpus-based comprehensive study on distribution of ba, so the core meanings defined previously can hardly cover all usage of ba. (3) There is a lack in phonetic research and verification on the various pragmatic function of ba. From the usage of ba in imperative sentences and with I love my family as the corpus material, this essay takes DP Theory as the theoretical framework and focuses on three questions: (1) What is the 
core grammatical meaning of ba in oral language? (2) How does it work in the regulatory mechanism of politeness in communication? and (3) How does its duration feature vary with the change of function? ( $I$ love my family is a reality-reflecting family sitcom based on the spoken language of Beijing people and highly suitable for our research and this essay.)

\section{Discourse Politeness Theory}

Discourse Politeness Theory, DP theory, a persuasive theory put forward by Mayumi (2002) based on Penelope Brown and Stephen Levinson's politeness theory. She stressed that discourse politeness should be studied as a whole and its dynamic pragmatic function in politeness should be studied from text level rather than a sentence or a speech act. She indicated that every discourse has its basic state and its typical state can be defined by calculating the proportion of a certain element in the whole conversation. She made a further indication that marked politeness and unmarked politeness can also be defined in the same way. Marked politeness refers to speech acts taken to avoiding or reducing face-threatening acts (FTA). Unmarked politeness refers to speech acts generally considered as approximate and acceptable acts. This theory mainly stands out with its taking both speaker and hearer into consideration in the process of calculating the De value of FTA, providing an equal that $\mathrm{Se}$ (Speaker's evaluation, $0 \leqq \mathrm{Se} \leqq 1$ ) - He (Hearer's evaluation, 0 $\leqq \mathrm{He} \leqq 1)=$ De. As is shown in Table 1 , when Se is far below $\mathrm{He}$, the speech acts are low-De-value acts, showing impoliteness with rudeness; when $\mathrm{Se}$ is far higher than $\mathrm{He}$, the speech acts are excess-De-value acts, showing impoliteness with lavish hospitality; and only when Se is basically the same as He, the speech acts are appropriate acts showing politeness. Both low-De-value acts and excess-De-value acts exert negative influences; only appropriate acts exert positive or moderately positive influences. With such comprehensive and persuasive analysis covering all kinds of speech acts, DP Theory has a great power in explaining speech acts phenomenon. Considering this, this essay takes DP Theory as the theoretical framework to make analysis of the pragmatic function of the sentence-final particle ba in imperative sentences.

Table 1. Range of De Value, Appropriateness of Speech Acts, the Effect of Politeness.

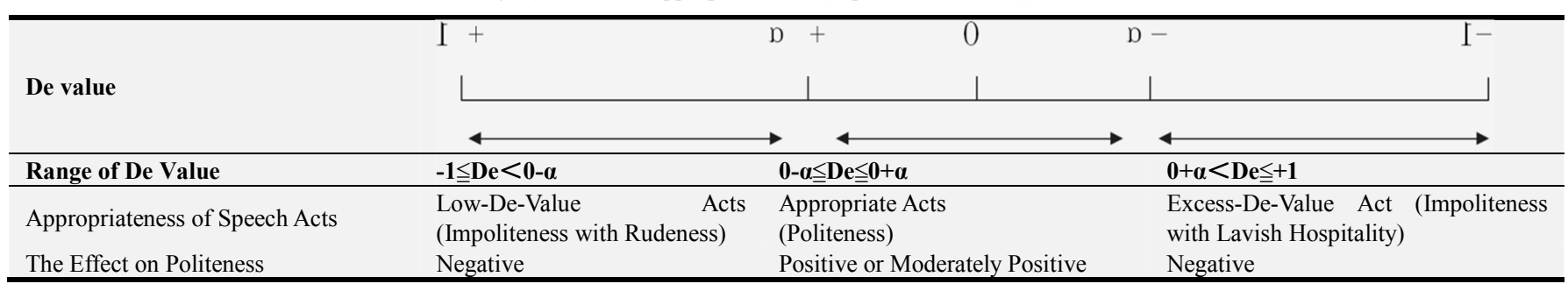

De Value:De=Se-He

$\alpha$ : Allowable deviation value

\section{The Distribution of Sentence-Final Particle Ba in Imperative Sentences}

Due to the differences in research perspectives, research methods and theories, researchers hold different opinions on the definition and classification of imperative sentences. As language is the synthesis of meaning, form and function, it is more reasonable to define imperative sentences from the perspectives of meaning, form and function: (1) Meaning: Imperative sentences express speaker's commands, suggestions, requests, etc.; (2) Form: Imperative sentences have unique grammatical form; (3) Function: Imperative sentences expresses the speaker's intention to make the hearer (or together) do or not do something. When it comes to the classification of imperative sentences, however, as language follows the same rule with all other things in the world that everything has its opposites, in linguistic performances there is always co-existence of commands and forbiddance, and of suggestions and dissuasions. So, the imperative sentences' meaning varied with the change of contexts. If imperative sentences are classified also from the perspectives of meaning, form and function, it may turn to be an excessively detailed classification lacking necessary logic and integrity. This essay, therefore, classified those imperative sentences expressing similar meaning and performing similar function with different tones of voice into the same category and present one kind of classification as following ${ }^{1}$ :

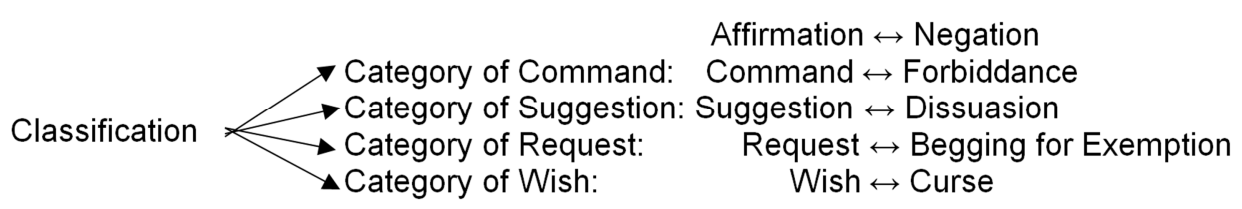

Figure 1. Classification of Imperative Sentences. 
category of request, and category of wish; and under each category there are two sub-categories from the perspective of affirmation and negation. Every category is a dynamic integration involving imperative sentences with different tones of voice. Command involves permission and requirement; forbiddance involves warning; suggestion involves negotiation, invitation and expression of impatience; wish involves summoning (because both wish and summoning express the speaker's strong expectation for the hearer); and curse involves swearing or cuss.

Based on the 210-thousand-words spoken language materials from the first 40 sets of I love my family, we built up a corpus containing all the imperative sentences from that and adapted the above classification to make an analysis:

Table 2. The Distribution of The Sentence-Final Particle Ba in Imperative Sentences.

\begin{tabular}{|c|c|c|c|c|c|c|c|c|c|}
\hline \multirow{2}{*}{$\begin{array}{l}\text { Classification of the } \\
\text { sentences }\end{array}$} & \multicolumn{2}{|c|}{ Category of Command } & \multicolumn{2}{|c|}{ Category of Suggestion } & \multicolumn{2}{|c|}{ Category of Request } & \multicolumn{2}{|c|}{ Category of Wish } & \multirow[b]{2}{*}{ Sum } \\
\hline & Command & Forbiddance & Suggestion & Dissuasion & Request & $\begin{array}{l}\text { Begging for } \\
\text { Exemption }\end{array}$ & Wish & Curse & \\
\hline Total Number of & 506 & 35 & 747 & 409 & 150 & 10 & 8 & 3 & 1868 \\
\hline Sentences & $27.09 \%$ & $1.87 \%$ & $39.99 \%$ & $21.90 \%$ & $8.03 \%$ & $0.54 \%$ & $0.43 \%$ & $0.16 \%$ & $100 \%$ \\
\hline Number of Sentences & 442 & 29 & 464 & 236 & 96 & 8 & 4 & 1 & 1280 \\
\hline without Particles & $87.35 \%$ & $82.86 \%$ & $62.12 \%$ & $57.70 \%$ & $64 \%$ & $80 \%$ & $50 \%$ & $33.33 \%$ & $68.52 \%$ \\
\hline Number of Sentences & 64 & 6 & 283 & 173 & 54 & 2 & 4 & 2 & 588 \\
\hline Number of Sentences & 9 & 0 & 195 & 11 & 28 & 0 & 3 & 2 & 248 \\
\hline with ba & $14.06 \%$ & $0 \%$ & $68.90 \%$ & $6.36 \%$ & $51.85 \%$ & $0 \%$ & $75 \%$ & $100 \%$ & $42.18 \%$ \\
\hline
\end{tabular}

* Percentages in the line "Total Number of Sentences" is the percentage of imperative sentences of respective category in the total number of sentences.

* Percentages in the line "Number of Sentences without Particles" is the percentage of imperative sentences without particles in the total number of sentences of respective category; and percentages in the line "Number of Sentences with Particles" is the percentage of imperative sentences with particles in the total number of sentences of respective category.

* Percentages in the line "Number of Sentences with ba" is the percentage of imperative sentences with ba in the total number of sentences with particles of respective category.

The table 2 above shows that except imperative sentences in the category of wish which is of strong subjective feelings, the percentages of sentences without particles have all reached or surpassed $50 \%$. So, it can be inferred that the basic state, also the unmarked politeness, of imperative sentences is without particles. The usage of particles emerges when the speaker feels the expression without particles shows inadequate politeness or emotion so it demonstrates marked politeness. Among all particles, ba is of the highest frequency, accounting $42.18 \%$ of the total usage of particles. With the statistics in the below table, following conclusions concerning distribution and tendency of ba: (1) The number of sentences expressing positive suggestions (in sub-category "Suggestion") is the largest among sentences with ba, which indicates that the core and typical use of ba is expressing suggestions; (2) Ba is rarely used in negative imperative sentences, especially in sentences expressing forbiddance or begging for exemption. The former reveals speaker's forcing hearer not to do something; and the latter means speaker's begging hearer not to do something to meet the speaker's interests. There exists no possibly in expressing these two meaning simultaneously with its core meaning. Therefore, ba is not used in these two kinds of imperative sentences. The similar problem also comes to sentences expressing dissuasion, so ba is sometimes used in such sentences but extremely rarely; (3) $\mathrm{Ba}$ is either rarely used in sentences expressing wishes while in the expression of strong subjective feelings is sentence-final particle like ba frequently used. Then, there comes another two questions: How does ba work in the adjustment of tone in sentences belonging to different categories of imperative sentence? What kind of politeness effect does ba achieve with different function respectively?
These will be explained as following.

\section{The Pragmatic Function of Imperative Sentences with ba}

\subsection{Positive Effect on Politeness: Moderate Tone and Show Respect}

It can be indicated from the above analysis that ba is most used in positive sentences expressing suggestions, which also proves the previous researchers' conclusion that the core meaning of ba is to indicate an underdetermined intention, "an intention that subject has for the object which is roughly clear yet remains underdetermined but available for negotiation." In imperative sentences, this intention mainly exists as "possibility of the negotiation on undetermined acts" [11]. This is distinctly embodied in imperative sentences expressing suggestion. Followings are illustrative sentences from I Love My Family:

1. He Ping: That is really frightening. Ah, why not bring Yan Hong's cat (ba)?

2. He Ping: Father, this is too much for your health. Let's hurry up to the hospital (ba)!

3. He Ping: Alas, still come in and sit down (ba)!

Sentence-final particle ba frequently appears with adverbs or phrases including still, why not, etc. Still means that the speaker has "experienced the process of making choices after full consideration" before telling hear the final choice [6]; and why not illustrates "the possibility and space for negotiation before final choice" [6]. These adverbs and phrases indicating underdetermination along with ba has achieved a positive 
effect on politeness of moderating tone and showing respect. For example, if ba is left in sentence 2, the tone will be too hard for communication between the young generation and the senior generation due to loss of respect; and in sentence 3, a sentence for suggestion and invitation, ba presents the possibility of negotiation and therefore moderates the tone and shows enough respect. "Come in and sit down" is the speaker's intention and ba makes it not a command but a suggestion which is also available for refusion. The usage of ba's core meaning here respects hearer's right of making choices and reduces sense of compulsion, producing positive effect on politeness.

\subsection{Positive Effect on Politeness: Moderate Tone and Show Sincerity}

In imperative sentences expressing request and summoning (wish), the sentence-final particle ba shows the speaker's sincerity simultaneously with moderating tone, expressing strong subjective feelings. Followings are illustrative sentences from I Love My Family:

4. Meng Chaoyang: Sister-in-law, please, give me a break, please (ba)!

5. He Ping: Zhiguo, Zhiguo, your father... alas, explain to your father for me, please (ba)!

6. Zhiguo: Sister Yanhong, this time it is exactly we that goes wrong. Forgive us this time, just this time, please (ba)!

7. Mr. Fu: Freedom finally comes! Freedom you have been long longing for finally comes! Hahaha! Cheer up for it (ba)! Sing for it (ba)! Hahaha!

Sentences 4, 5 and 6 are sentences expressing request. Due to the high sincerity of these requests, absence of ba will make sentences feel like fragments and create a tough tone unable to convey such sincerity. In such case when sentences expressing strong request, the meaning of ba is closer to the subjective feelings of speaker than its core meaning. Since speaker's request may trouble the hearer, ba is often used together with verbs with implication of making attempts (like "explain" in sentence 5) to enhance politeness or with adverbs increasing certainty (like "just" in sentence 6) to enhance the power of request. For sentences expressing summoning (wish) like sentence 7 , ba expresses speaker's strong wishes and conveys strong subjective feelings, positively letting hearer execute instructions with moderate tone.

\subsection{Moderately Positive Effect on Politeness: Moderate Tone and Reduce Impoliteness}

Some researchers hold the opinion that ba should not be used in sentences expressing command since the core meaning of ba lies in uncertainty and underdetermination while commands require hearer's absolutely obeying words of speaker, who is always of higher class like boss or from senior generation. Followings are illustrative sentences from I Love My Family:
8. Zhixin: Stop!
* Stop (ba)!
9. Mr. Fu: (Shout aloud) Police! Call the police! 110! 110!

* (Shout aloud) Police! Call the police (ba)! 110! 110!

10. Mr. Fu: (Extremely angry) Can you get out now? Scram! Scram!

* (Extremely angry) Can you get out now? Scram (ba)! Scram (ba)!

Sentence 8 and 9 came up when decoration workers in $\mathrm{Mr}$. Fu's house for decorating scatter the decoration materials here and there rudely. Zhixin and Mr. Fu got so anxious that they gave clear and strong command as sentence 8 and 9 . If ba is added to these two sentences, it adds possibilities of negotiation and refusing to execute the instructions. So, ba is not suitable here. Sentence 10 is an instruction coming out when speaker is extremely angry. If ba is added to this sentence, such anger will fail to convey. Generally speaking, if there are modal verbs like must, need, should etc. in a sentence, ba is not suitable for this sentence; but this is not absolute. Followings are illustrative sentences from I Love My Family:

11. Male police: Say (ba)! / Say!

12. Mr. Fu: You can run away in no means actually! Considering your attitude was not bad that day, I would not mention it; but if this happens again, I will punish you both for this and that time. If necessary, I may also turn to your company. Go now (ba)! / Go!

Sentence 11 came up when police investigated the theft at the home of the Zhixin, who was suspected because he accepted the lost BP from his friend who was just the thief. Zhixin's contradictory words arose impatience from the police's mind but due to uncertainty about Zhixin's identity, the police did not use tone as rough as "Say" which was normally used in judging a criminal and turned to ba to moderate tone and indicate impatience. Sentence 12 was $\mathrm{Mr}$. Fu's critique on the nanny Zhang. "Go" alone is too rough tone and ba here can moderate it simultaneously with extending the impatience. In these cases, it is perceptible that although ba is used, it does not introduce possibility of negotiation but becomes a carrier and diluent of the negative feelings of speaker including strong negative subjective feelings like impatience. In addition, the "ba" in sentences expressing dissuasion can produce similar effects. Followings are illustrative sentences from I Love My Family:

13. Mr. Fu: We are both senior leaders so it is unnecessary to do harm to each other for these trifles. So, after intensive struggle within myself, I suggest you not attend this selection for the title of honor "Healthy Elderly" (ba).

14. Zhiguo: Zhixin, stop your gossip (ba).

Dissuasion is a verbal act that may bring shame on others easily. So, in sentences expressing dissuasion, ba will effectively avoid dissuasion becoming tough prohibition or command and therefore avoid impoliteness with moderate tone. However, it should be noticed that even ba can moderate tone and reduce impoliteness, the hearer may still feel unpleasant due to the speaker 's command in words of strong sense of compulsion without considering hearer's feelings. Although ba introduces the possibility of negotiation, in sentences expressing dissuasion, the speaker will inevitably offend hearer's right of making choices. 
Therefore, ba can only produce moderately positive effect on politeness.

\subsection{Negative Effect on Politeness: Moderate Tone and Express Negative Feelings}

In addition to moderating tone and enhancing politeness, ba can also express strong sarcasm, impatience and even curses. In this context, the speaker takes little regard for the face of the hearer and tends to use rough tone, producing negative effect on politeness. Followings are illustrative sentences from $I$ Love My Family:

15. Zhixin: All is OK. I want to play the bass drum tomorrow so I will learn a trick from my grandma. You will feel amazed then!

Peace: You want to play the bass drum with such voice? Forget it (ba)!

16. Xiao Cui: Isn't it a rip-off? I'm going back to Family Ma! Maybe they want me back!

Zhixin: Stop your daydreaming (ba)!

17. You go to hell (ba)!

For all three sentences above, the negative feelings will get stronger without ba and so is impoliteness; but even with ba's function in moderating tone, those negative feelings and impoliteness still remains, reflecting speaker's taking no regard of the face of hearer and focusing more on the expression of true feelings. This case may take place either between close friends or relatives as sentence 15 or there exist deep disagreement in power, interests etc. between the speaker and hearer as Zhixin's treatment on the neighbor's mischief-making nanny in sentence 16 and curses out of extreme anger in sentence 17.

The above analysis reveals that the core pragmatic function of the sentence-final particle ba is moderating tone, producing both positive effect on politeness by enhancing it and negatice effect on politeness by ignoring the face of hearer. The relation between euphemism and politeness is not a one-to-one corresponding relation. Euphemism is defined from the perspective of internal tone and language force of sentence while politeness is defined from the perspective of external context of sentence and response and feelings of both speaker and hearer. The core meaning of ba, indication of an underdetermined intention, also varies in degree with the change of context, function and degree of subjective; the grammatical function of ba matters in different degree accordingly. The core meaning is best embodied in imperative sentences belonging to categories of suggestion but weakened in imperative sentences belonging to categories of command, request and wish and ba therefore becomes a moderator of tone and carrier of speaker's feelings.

\section{The Duration Features of Imperative Sentences with ba}

The above part of this essay makes description of and analysis on the co-occurrence and pragmatic function of sentence-final particle ba in different category. Then how does its duration feature vary with the change of function? In order to make further verification of the rationality of the categories of imperative sentences and the pragmatic function of the ba in imperative sentence, this essay classify the commonly-used functions of the sentence-final particle ba into eight categories: command, permission, urging, suggestion, invitation, helplessness, demand, impatience. The design of the reading material of test is also based on this classification. (Due to the low frequency of ba in decussation and low frequency of imperative sentences expressing wish, we do not involve imperative sentences expressing decussation and wish in the material for test.) In order to enable the research subjects express themselves in a natural state as much as possible, the selected conversation was close to daily life in the design of language examples, accompanied by background explanation. Research subjects made record after being enough acquaint with the reading materials. Research subjects of this experiment consisted of 16 males and 16 females from Jinan University, including the freshmen and sophomores from Broadcasting \& Hosting Art, graduate students from Chinese Language \& Literature, and junior and senior students from the TCSOL (Teaching Chinese to Speakers of Other Language). Research subjects had all got at least 2B in PSC (PUTONGHUA SHUIPING CESHI, a test to qualify the level of spoken Putonghua. The recording was completed in the recording room of the College of Chinese Language and Culture of Jinan University. The speech signal was directly imported into the computer. CoolEditPro was the recording software to record the sound. The sampling rate was $116 \mathrm{kHz}$ and files were saved as wav file. There were 32 example sentences for every student. Each student read the sentence from the beginning to the end and finally a recording of 1024 example sentences was produced. The experiment was conducted from June to August 2014.

To test whether the duration of the sentence-final particle ba can distinguish different functions or not, we recorded the duration of the ba based on the recording. Each function is designed with four sentences. These four sentences are designed into a set of sentences consisting ba and verbs with four tones in Chinese (说 (say) for upper even, 来 (come) for lower even, 走 (walk) for rising tone and 去 (qu) for falling tone). Each sentence was read and recorded by all 32 research subjects so for every function there are 64 recordings. Table 3 shows the average duration and standard deviation of sentence-final particle ba in different function.

Table 3. The Duration of Sentence-final Particle Ba (Unit: second).

\begin{tabular}{|c|c|c|c|c|c|c|c|}
\hline \multicolumn{4}{|c|}{16 Females } & \multicolumn{4}{|l|}{16 Males } \\
\hline Function & $\begin{array}{l}\text { Number of } \\
\text { Observation }\end{array}$ & Average Duration & $\begin{array}{l}\text { Standard } \\
\text { Deviation } \\
\end{array}$ & Function & Number of Observation & $\begin{array}{l}\text { Average } \\
\text { Duration } \\
\end{array}$ & $\begin{array}{l}\text { Standard } \\
\text { Deviation }\end{array}$ \\
\hline Command & 64 & 0.155 & 0.0088 & Command & 64 & 0.1421 & 0.0038 \\
\hline Permission & 64 & 0.1663 & 0.0137 & Permission & 64 & 0.1491 & 0.0131 \\
\hline Urging & 64 & 0.1821 & 0.0159 & Suggestion & 64 & 0.1591 & 0.0117 \\
\hline
\end{tabular}




\begin{tabular}{llllllll}
\hline 16 Females & & & 16 Males & & Average \\
Function & $\begin{array}{l}\text { Number of } \\
\text { Observation }\end{array}$ & Average Duration & $\begin{array}{l}\text { Standard } \\
\text { Deviation }\end{array}$ & Function & Number of Observation & $\begin{array}{l}\text { Stand } \\
\text { Duration } \\
\text { Deviation }\end{array}$ \\
\hline Suggestion & 64 & 0.1835 & 0.0036 & Invitation & 64 & 0.1603 & 0.0354 \\
Invitation & 64 & 0.1873 & 0.0273 & Urging & 64 & 0.1703 & 0.0095 \\
Impatience & 64 & 0.1979 & 0.0451 & Helplessness & 64 & 0.1775 & 0.0344 \\
Helplessness & 64 & 0.2016 & 0.0564 & Impatience & 64 & 0.1865 & 0.0543 \\
Request & 64 & 0.2688 & 0.0596 & Request & 64 & 0.2144 & 0.0492 \\
\hline
\end{tabular}

Table 4. Two-way ANOVA of different functions.

\begin{tabular}{lllllll}
\hline Source of Differences & SS & df & MS & F & P & P-value \\
\hline Function & 0.718998 & 7 & 0.102714 & 29.78474 & 0.0000 & 2.018647 \\
Gender & 0.137039 & 1 & 0.137039 & 39.7383 & 0.0000 & 3.850701 \\
Interaction & 0.048689 & 7 & 0.006956 & 2.016954 & 0.050204 & 2.018647 \\
Internal & 3.476131 & 1008 & 0.003449 & & & Interaction \\
Total & 4.380857 & 1023 & & & & Internal \\
\hline
\end{tabular}

Table 5. Variance analysis of Different Functions in Category of Command (Female).

\begin{tabular}{llllll}
\hline Source of Differences & SS & df & MS & F & P-value \\
\hline Interblock & 0.004131 & 1 & 0.004131 & 2.839795 & 0.094431 \\
Intra-group & 0.183308 & 126 & 0.001455 & & \\
Total & 0.187439 & 127 & & \\
\hline
\end{tabular}

Table 6. Variance analysis of Different Functions in Category of Command (Male).

\begin{tabular}{llllll}
\hline Source of Differences & SS & df & MS & F & P-value \\
\hline Interblock & 0.001566 & 1 & 0.001566 & 0.84577 & 0.359509 \\
Intra-group & 0.233262 & 126 & 0.001851 & & 3.916325 \\
Total & 0.234828 & 127 & & \\
\hline
\end{tabular}

Table 7. Variance analysis of Different Functions in Category of Suggestion (Female).

\begin{tabular}{llllll}
\hline Source of Differences & SS & df & MS & F & P-value \\
\hline Interblock & 0.021576 & 4 & 0.005394 & 1.643073 & 0.163206 \\
Intra-group & 1.034091 & 315 & 0.003283 & & \\
Total & 1.055667 & 319 & & & \\
\hline
\end{tabular}

Table 8. Variance analysis of Different Functions in Category of Suggestion (Male).

\begin{tabular}{llllll}
\hline Source of Differences & SS & df & MS & F & P-value \\
\hline Interblock & 0.034665 & 4 & 0.008666 & 2.343255 & 0.054796 \\
Intra-group & 1.164988 & 315 & 0.003698 & & \\
Total & 1.199652 & 319 & & \\
\hline
\end{tabular}

From the above table, it can be concluded that the duration of sentence-final particle ba clearly reflects the feature of ba in different category. Command and Permission belong to category of command. Since this category carries less subjective feelings and need short phonetic feature to enhance executive power, the duration of this category is the shortest. Urging, Suggestion, Impatience and Helplessness belong to category of suggestion. Impatience and Helplessness carry more subjective feelings so duration becomes longer. Among these different functions, duration of ba of Request is the longest and accordingly the subjective feelings it carries is the strongest. Based on Table 3, further multiple comparison was made to verify whether duration would distinguishingly differ with function. It turns out that $\mathrm{P}$ values of category of command, suggestion and request (longest duration) are all below 0.05, indicating distinguishing difference, which proves that duration can be used in distinguishing function. Among the same category, ba with different function turns to possess similar duration ${ }^{1}$.
This, to some extent, also indicates the duration features of sentence-final particle ba:(1) The stronger the subjectivity is, the stronger the tone is so the longer the sound length is; (2) Duration of sentence-final particle in imperative sentences belonging to different category differ distinguishingly; (3) Among same category, ba with different function, although differs a little due to the differences in subjectivity, turns to possess similar duration. These conclusions have verified the rationality of classification of this essay.

1: We first adopted Two-way ANOVA in the test of the 8 sets of different functions. Interaction $\mathrm{F}=2.01869, \mathrm{P}=0.0502$; between different functions, $\mathrm{F}=29.7847, \mathrm{P}=0.0000$; between different genders, $\mathrm{F}=39.7383, \mathrm{P}=0.0000$. $\mathrm{P}$ values between different functions and genders are both largely below 0.05 , proving that duration of different functions and genders is of great difference. Later, we made ANOVA in the test of the 8 sets of different gender for each function in same category respectively. Category of command: Female: $\mathrm{F}=2.8397$, $\mathrm{P}=0.0944$; Male: $\mathrm{F}=0.84577, \mathrm{P}=0.3595$. Both $\mathrm{P}$ values 
surpassed 0.05 , indicating no distinguishing difference exists in the duration of ba of function of command and permission. Category of suggestion: Female: $\mathrm{F}=1.6431, \mathrm{P}=0.1632$; Male: $\mathrm{F}=2.3433, \mathrm{P}=0.0548$. Both $\mathrm{P}$ values surpassed 0.05 , indicating no distinguishing difference exists in the duration of ba of function of urging, suggestion, invitation, helplessness and impatience. More statistics are shown in Schedule 1 5.

\section{Conclusion}

Through the description of the distribution of ba in imperative sentence, the analysis of pragmatic function with DP theory and phonetic experiment of prosodic features, there comes up with following conclusions. Firstly, from the perspective of research methods, no language form is independent. There exist co-occurrence, relations in meaning and feature, pragmatic functions and phonetic features. Studying features of sentence-final particles from a comprehensive perspective of form, semantics, pragmatics and phonetics can be a better way of studying features of sentence-final particles. In studying its core meaning and characteristics, the application conditions of ba can be studied from three perspectives, positive, neutral and negative. Its grammatical meaning and pragmatic function can be studied by studying co-occurrence of semantics and pragmatics of co-occurrence adverb, auxiliary verbs, discourse relations etc.

Table 9. Summary of The Usage of Modal Particle Ba.

\begin{tabular}{|c|c|c|c|c|c|}
\hline Category & Function & $\begin{array}{l}\text { Permissibility } \\
\text { for Usage }\end{array}$ & Pragmatic Function & Co-occurrence & $\begin{array}{l}\text { Duration } \\
\text { Features }\end{array}$ \\
\hline \multirow{2}{*}{$\begin{array}{l}\text { Category of } \\
\text { Command }\end{array}$} & Command & $\circ$ & $\begin{array}{l}\text { Moderate Tone, Moderately } \\
\text { Positive Effect }\end{array}$ & $\begin{array}{l}\text { No co-occurrence with modal verbs like must, } \\
\text { need etc. }\end{array}$ & shortest \\
\hline & Forbiddance & $x$ & 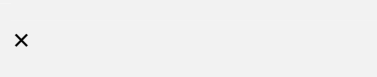 & $\begin{array}{l}\text { No co-occurrence with words expressing } \\
\text { forbiddance like not allowance, forbiddance etc. }\end{array}$ & $x$ \\
\hline \multirow{2}{*}{$\begin{array}{l}\text { Category of } \\
\text { Suggestion }\end{array}$} & Suggestion & ○ $\mathrm{r}$ & Moderate Tone, Positive Effect & $\begin{array}{l}\text { Co-occurrence with adverbs or phrases like still, } \\
\text { why not etc. }\end{array}$ & long \\
\hline & Dissuasion & $\circ$ & $\begin{array}{l}\text { Moderate Tone, Moderately } \\
\text { Positive Effect }\end{array}$ & $\begin{array}{l}\text { Co-occurrence with words like do not, free from } \\
\text { etc. }\end{array}$ & - \\
\hline \multirow{2}{*}{$\begin{array}{l}\text { Category of } \\
\text { Request }\end{array}$} & Request & $\circ$ & Moderate Tone, Positive Effect & $\begin{array}{l}\text { Co-occurrence with adverbs increasing certainty } \\
\text { like just }\end{array}$ & longest \\
\hline & $\begin{array}{l}\text { Begging for } \\
\text { Exemption }\end{array}$ & $\circ$ & $x$ & $\begin{array}{l}\text { No co-occurrence with words like please not } \\
\text { etc. }\end{array}$ & - \\
\hline \multirow{2}{*}{$\begin{array}{l}\text { Category of } \\
\text { Wish }\end{array}$} & Wish & $x$ & Moderate Tone, Positive Effect & $\begin{array}{l}\text { Co-occurrence with verbs like let, make, have, } \\
\text { may etc. }\end{array}$ & $x$ \\
\hline & Curse & $\circ$ & Moderate Tone, Negative Effect & $\begin{array}{l}\text { Co-occurrence with negative words like never, } \\
\text { daydream, etc. }\end{array}$ & - \\
\hline
\end{tabular}

* () $\mathrm{r}$ represents that "ba" has the highest frequency in this function; $\circ$ represents that "ba" can be used; $\times$ represents that "ba" cannot be used; — represents that there is no relevant data exists

Secondly, from the perspective of DP theory, communication is a continuum throughout the positive, moderate and negative effects on politeness. It can be concluded that people do not always follow the principle of cooperation and principle of politeness in practical communication with the analysis of the pragmatic functions of "ba" in the imperative sentence. In some certain circumstances, there are many rude and impolite language forms ignoring others' face. This also verifies the effectiveness of DP theory in practical language applications. Thirdly, according to the research, although ba has its core meaning, it also varies in degree with the change of context, function and degree of subjectivity. The change of meaning is not limited in different categories, but also some trifle but existing differences between different usage within same category. The result of phonetic experiments also proves this. In research, both core meaning and flexible application in various context should be paid attention to in order to better grasp the principle of distribution and diversity of function of function words. This essay makes tentative empirical study and there still requires further improvement. The choice of corpus needs to be further expanded, and the oral corpus of different themes should be selected so as we can observe and grasp the usage and function of ba in a more comprehensive way. In the experimental design, we also need to further cover all usages of ba, observe its various sorts of prosodic features such as length, intonation under the different functions and provide a beneficial reference and practicable pattern for the bilingual teaching.

\section{Acknowledgements}

The paper is funded by "Comparative Study of Language Strategies of Chinese and Japanese Imperative Sentences from the Perspective of Multimodality" of Ministry of Education Humanities and Social Sciences Research Project 2017 Youth Fund Project (Grant ID: 17YJC740016)

\section{References}

[1] Ding Shengshu (1961), The Talk on Modern Chinese Grammar. Beijing: The Commercial Press.

[2] Li Jinxi (1924), New Grammar of Modern Chinese. Changsha:Hunan Education Publishing House.

[3] Wang Li (1943), Modern Grammar of Chinese. Beijing:The Commercial Press. 
[4] Zhao Yuanren (1979), A Grammar of Spoken Chinese. Beijing:The Commercial Press.

[5] Zhu Dexi (1982), The Lecture Notes of Grammar. Beijing:The Commercial Press.

[6] Lü Shuxiang (eds.) (2003), Eight Hundred Words of Modern Chinese Language. Beijing: The Commercial Press.

[7] Qu Chengxi \& Li Bin. Translating mod - ern Chinese utterance-final particles into English:a case study of the discourse function of ba. Foreign Language Research. 2004, pp. 6.

[8] Sun Rujian. Four functions of the toned words at the end of sentences. Journal of Nantong University (Social Sciences Edition). 2005, pp. 2.

[9] Xu Jingning. Modality interpretation for the tone particle "ba". Journal of Peking University (Philosophy and Social Sciences). 2003, pp. 4.
[10] Zhang Xiaofeng (2003), A Discourse Analysis of Mood Particle ba, ne, and a in Mandarin Chinese. Ph.D. Thesis, Shanghai Normal University.

[11] Zhao Chunli \& Sun Li. On the distributional verification and semantic extraction of the sentence- final particle ba. Studies of the Chinese Language. 2015, pp. 2.

[12] $\mathrm{Hu}$ Mingyang. Modal particle and interjection of Beijing dialect. Studies of the Chinese Language. 1981, pp. 5-6.

[13] Lu Jianming, Interrogative particles in modern Chinese. Studies of the Chinese Language. 1984, pp. 5.

[14] Ran Yongping. Pragmatic functions of the Chinese discourse marker ba and its contextual adaptability. Modern Foreign Language. 2004, pp. 4.

[15] Usami Mayumi. The development of Discourse Politeness Theory1- 12. Gengo Selections. 2002, pp. 1. 